\title{
IMPLEMENTASI POWER SEARCHING DENGAN SIMBOL MATEMATIKA UNTUK OPTIMALISASI HASIL PENCARIAN REFERENSI PADA SISWA SMKN II TALUK KUANTAN
}

\author{
${ }^{1)}$ Diki Arisandi, ${ }^{2}$ Sukri, ${ }^{3)}$ Salamun, ${ }^{4)}$ Roni Salambue \\ 1),2),3) Program Studi Teknik Informatika, Fakultas Teknik, Universitas Abdurrab \\ 4)Program Studi Sistem Informasi, Fakultas Matematika dan Ilmu pengetahuan Alam, \\ Universitas Riau \\ Surel: ${ }^{1)} \underline{\text { diki@ univrab.ac.id }},{ }^{2)}$ sukri@ univrab.ac.id,${ }^{3)}$ salamun@ @nivrab.ac.id,
}

\begin{abstract}
Access to information from the internet is become the thing that is needed by almost all society, and also the student of SMK N II Taluk Kuantan. In this community service, the material that has been given is about how the search results obtained to be more effective by using power searching. Power searching delivered to students of SMK N II Taluk Kuantan is by inserting mathematical symbols on the keywords entered into the search engine on the internet. In addition, the material also discussed about more specific search by combining mathematical symbols, host names and file types to search. The method In this community service was giving the material and demo about how the implementation of power searching on search engines. After this activity is implemented, the community service team evaluates the material that has been given before. The result was the students in SMK N II Taluk Kuantan can implement power searching well. 1
\end{abstract}

Key words: mathematical symbols, internet, search engine, keywords, power searching.

\begin{abstract}
ABSTRAK
Akses informasi yang berasal dari internet pada saat ini menjadi hal yang dibutuhkan oleh hampir seluruh masyarakat, tidak terkecuali siswa SMK N II Taluk Kuantan. Pada kegiatan pengabdian ini, diberikan materi tentang bagaimana hasil pencarian yang didapat menjadi lebih efektif dengan menggunakan power searching. Power searching yang disampaikan pada siswa SMK N II Taluk Kuantan yaitu dengan menyisipkan simbol matematika pada kata kunci yang dimasukkan ke mesin pencari di internet, selain itu diberikan materi tentang pencarian yang lebih spesifik dengan memadukan simbol matematika, nama host dan jenis file yang dicari. Kegiatan pengabdian berupa pemberian materi dan demo tentang bagaimana implementasi power searching pada mesin pencari. Setelah kegiatan ini dilaksanakan, tim pengabdian mengadakan evaluasi atas materi yang telah diberikan. Hasilnya, siswa di SMK N II Taluk Kuantan dapat mengimplementasikan power searching dengan baik.
\end{abstract}

Kata kunci:simbol matematika, internet, mesin pencari, kata kunci, power searching. 


\section{PENDAHULUAN}

Pencarian informasi secara Onlinesaat ini sudah semakin banyak diketahui dan digunakan. Makin banyak juga penyedia layanan jenis ini yang tersedia dan dengan mudah ditemukan di internet. Situs pencarian informasi secara online cukup banyak memberikan kemudahan bagi pengguna internet dalam mencari informasi yang dibutuhkan. Pada saat ini, lebih banyak masyarakat didaerah kota besar dalam menggunakan situs pencarian informasiOnline(Tyas $d k k$, 2016), sementara itu masyarakat didaerah seperti kota kecil atau pedesaan masih banyak yang belum dapat menggunakan dikarenakan belum mempunyai tingkat pengetahuan dan infrastruktur yang memadai (Wahyono, 2011).

Dalam dunia pendidikan kegiatan mencari informasi ataupun referensi belajar sangat dibutuhkan, khususnya untuk siswa sekolah menengah atas maupun kejuruan. Hal ini menjadi penting karena referensi yang didapat dari internet melalui bantuan situs pencarian online dapat menunjang pengetahuan dan keahlian yang dimiliki, disamping pengetahuan yang bersumber dari buku pelajaran maupun yang didapat dari Guru (Hamka, 2015). Jika dilihat dari perkembangan teknologi akses informasi yang didapat dari hasil pencarian tidak lagi hanya berbasis teks namun juga berbasis multimedia, sehingga memudahkan siapa saja untuk mepelajari informasi yang didapat, dan tentunya dapat diakses oleh siapa saja dan kapan saja(Suartama, 2010).

Dalam menggunakan situs pencarian informasi, pengguna diminta untuk memasukkan kata kunci agar hasilnya dapat dilihat dan diakses. Namun agar hasil pencarian sesuai dengan yang dikehendaki dan tidak memunculkan hasil yang tidak diinginkan, maka perlu sebuah teknik pencarian yang bernama power searching. Teknik power searching merupakan sebuah teknik pencarian informasi pada situs pencari dengan menyisipkan tambahan pada kata kunci yang dimasukkan seperti karakter spesial ataupun simbol matematika (Indrajit, 2002). Dengan menggunakan teknik power searching ini, hasil yang akan dimunculkan bisa lebih akurat dan meminimalisir hasil pencarian yang tidak perlu, sehingga tidak terjadi "banjir informasi" atau information overload (Maretina, 2016).

Sekolah SMKN 2 Taluk Kuantanberalamat di Kabupaten Kuantan Singingi, Provinsi Riau. Siswa yang bersekolah di SMKN 2 Taluk Kuantandan memilih bidang rekaysasa teknik dapat memilih bidang ilmu keahlian Teknik Komputer dan Jaringan, teknik otomotif dan teknik mesin. Sekolah SMKN 2 Taluk Kuantanberada pada sebauh kota kecil dan sudah memiliki fasilitas jaringan internet namun masih minim, penggunaannya masih terbatas dan bandwidth yang ada kurang dari $10 \mathrm{Mbps}$. Dengan keadaan yang telah dijelaskan sebelumnya, akses internet SMKN 2 Taluk Kuantan sangat terbatas, baik dari sisi avabilitas maupun konektivitas menyebabkan akses untuk mendapatkan sumber informasi dari internet menjadi terbatas juga. Walaupun memiliki keterbatasan, namun siswa di SMKN 2 Taluk Kuantan memiliki semangat yang tinggi dalam mencari ilmu dan mencari informasi di internet. Hal ini dapat terlihat dari pengamatan awal yang dilakukan ketika tim pengabdian tiba di lokasi, dimana banyak didapati siswa yang memiliki ekonomi yang mapan membawa laptop bahkan membawa modem internet pribadi dan bersama dengan teman-temannya mencari referensi belajar disaat waktu luang.

\section{BAHAN DAN METODE}


Kegiatan pengabdian ini dilaksanakan di SMK N II Taluk Kuantan, Kabupaten Kuantan Singingi. Kegiatan yang diadakan berupa transfer knowledge kepada siswasiswi yang ada disana.Transfer knowledge yang dilakukan berupa ceramah, dilanjutkan dengan pemaparan langsung berupa demo menggunakan laptop yang terkoneksi dengan internet agar siswa dapat melihat hasil pencarian menggunakan power searching. Kegiatan diakhiri dengan diskusi, tanya jawab, pembagian door prize bagi yang dapat memberian tanggapan dan foto bersama dengan audiens yang hadir pada acara tersebut.

Keseluruhan waktu kegiatan pengabdian ini dilakukan selama 5 bulan, yaitu dimulai dari tanggal 1 September 2016 hingga 14 Januari 2017. Tahapannya dapat dilihat pada tabel berikut:

Tabel 1. Jadwal Pelaksanaan

\begin{tabular}{|l|l|l|l|l|l|}
\hline Jenis Kegiatan & Bulan 1 & Bulan 2 & Bulan3 & Bulan4 & Bulan5 \\
\hline Penentuan Tema & $\sqrt{ }$ & & & & \\
\hline $\begin{array}{l}\text { Perencanaan\& } \\
\text { Survey Lokasi }\end{array}$ & & $\sqrt{ }$ & $\sqrt{ }$ & & \\
\hline Pelaksanaan & & & & $\sqrt{ }$ & \\
\hline Evaluasi\&Pelaporan & & & & & $\sqrt{ }$ \\
\hline
\end{tabular}

\section{HASIL DANPEMBAHASAN}

Pada tahap awal pelaksanaan, kegiatan dimulai dari penentuan tema yang akan dibawakan untuk kegiatan pengabdian ini. Penentuan tema power searching didasari atas semangat kebutuhan siswa SMK N II Taluk Kuantan dalam belajar, terutama mencari referensi tambahan diluar yang diajarkan oleh gurunya. Power searching yang digunakan dalam kegiatan ini yaitu dengan menyisipkan simbol matematika $(+,-, /, *$, And, Or) pada kata kunci yang dimasukkan, fungsinya agar hasil pencarian yang muncul lebih efektif (Wahono, 2008).

Setelah penentuan tema ditentukan, kegiatan selanjutnya yaitu perencanaan kegiatan dan survey lokasi. Perencanaan kegiatan melibatkan bapak Yusfig, M.Kom Selaku Ketua Jurusan Teknik komputer dan Jaringan di SMK N II Taluk Kuantan. Setelah beberapa kali koordinasi dengan beliau, disarankan kegiatan sebaiknya dilaksanakan pada hari Sabtu pada pertengahan bulan Januari. Hal ini didasari bahwa pada hari Sabtu di pertengahan bulan Januari, para Siswa belum melakukan Ujian dan kegiatan belajar tidak terlalu padat.

Survey lokasi awal dilakukan tidak langsung ke tempat pelaksanaan kegiatan, melainkan mencari informasi dari salah satu Mahasiswa Prodi Teknik Informatika bernama Sri Novika Sari yang merupakan alumni dari SMK N II Taluk Kuantan. Informasi yang didapat yaitu keadaan lokasi, tempat yang memungkinkan untuk dilaksanakan kegiatan, keadaan siswa di SMK N II Taluk Kuantan, jarak tempuh dan ketersediaan akses internet selama di lokasi.

Berdasarkan penuturan Sri Novika Sari, jarak tempuh menuju ke lokasi diperkirakan selama 3 hingga 4 jam. Hal ini juga dapat dilihat dari peta digital dari google maps yang memperkirakan jarak tempuh ke lokasi seperti gambar berikut: 


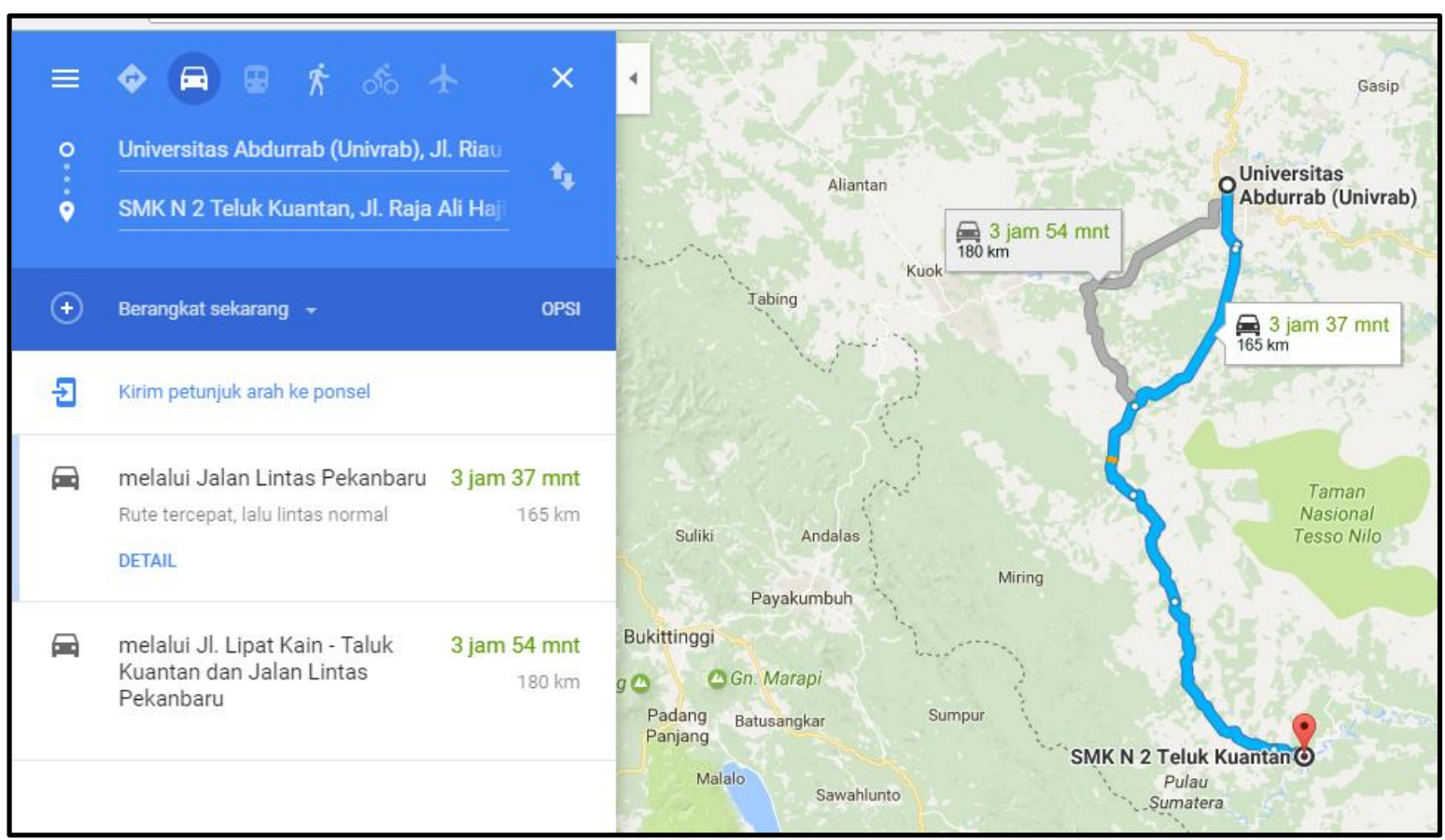

\section{Gambar 1. Jarak Tempuh Ke Lokasi}

Selain gambaran waktu dan jarak tempuh yang dibutuhkan, tim juga melihat gambaran kondisi ketersediaan akses internet di sekitar SMK N II Taluk Kuantan dengan menggunakan bantuan halaman website https://opensignal.com/ , berikut gambaran akses internet disekitas lokasi kegiatan:

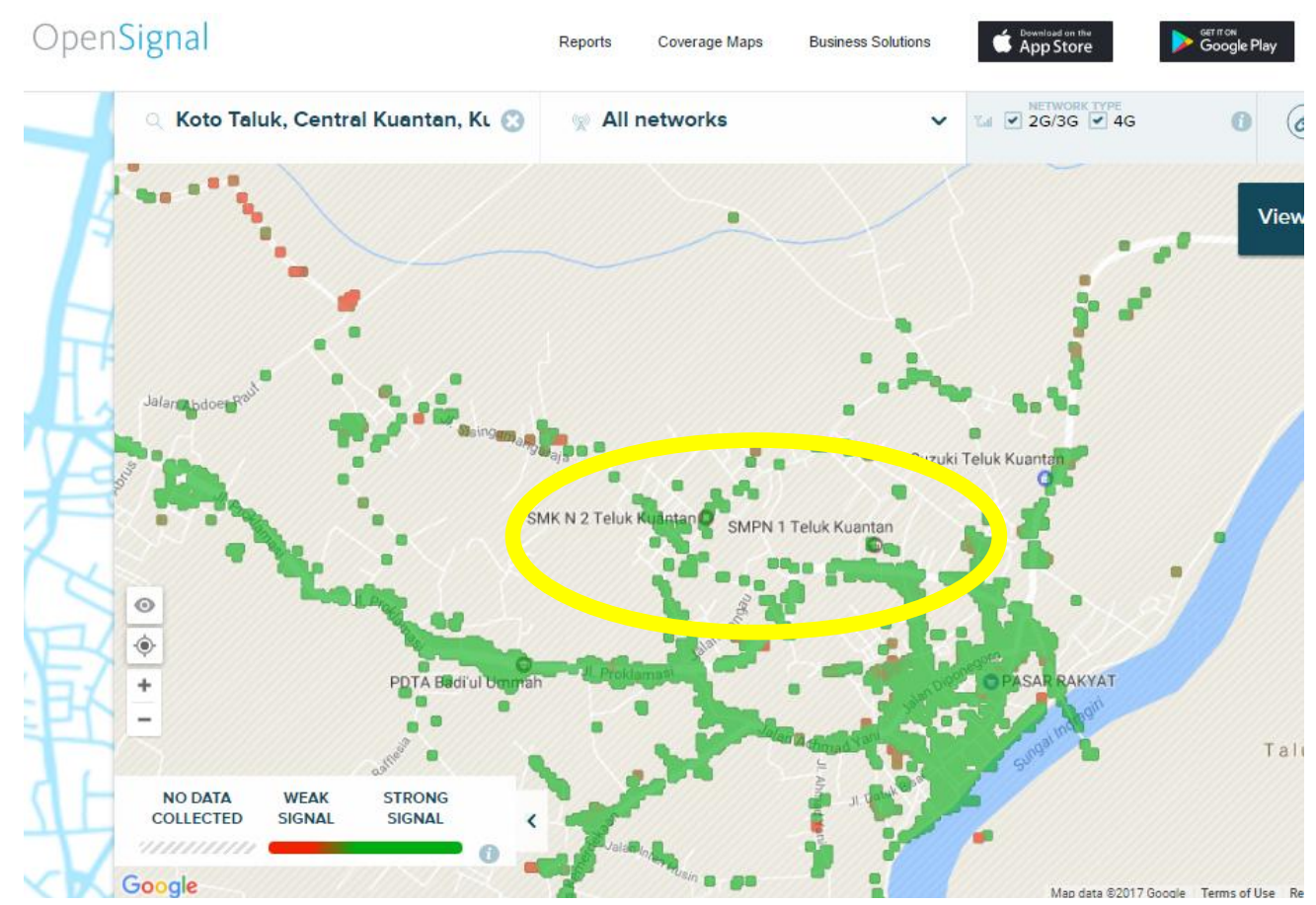

\section{Gambar 2. Ketersedian Akses Internet Disekitar Lokasi (Lingkaran Kuning)}

Dari gambar 2 dapat dilihat bahwa untuk ketersediaan akses internet di sekitar lokasi kegiatan cukup baik untuk dilaksanakan kegiatan pengabdian ini, Terlihat bahwa area yang memiliki kualitas layanan intenet yang baik diberi tanda hijau, dan dapat dilihat juga 
bahwa SMK N II Taluk Kuantan berada didaerah yang diberi tanda hijau.Gambaran tentang ketersediaan layanan internet perlu diketahui karenapada pada saat sesi demo, penggunaan internet diperlukan agar siswa dapat langsung melihat hasil pencarian dari Power Searching ini.

Tahap pelaksanaan kegiatan dilaksanakan pada tanggal 4 januari 2017. Namun sehari sebelum pelaksanaan, pada tanggal 3 Januari 2017 tim melakukan pengecekan ruangan yang dipakai sekaligus pemasang spanduk. Pada hari pelaksanaan siswa-siswi dikumpulkan di aula SMK N II Taluk Kuantan untuk mendengarkan pemaparan dari tim pengabdian masyarakat seperti yang terlihat pada gambar berikut:

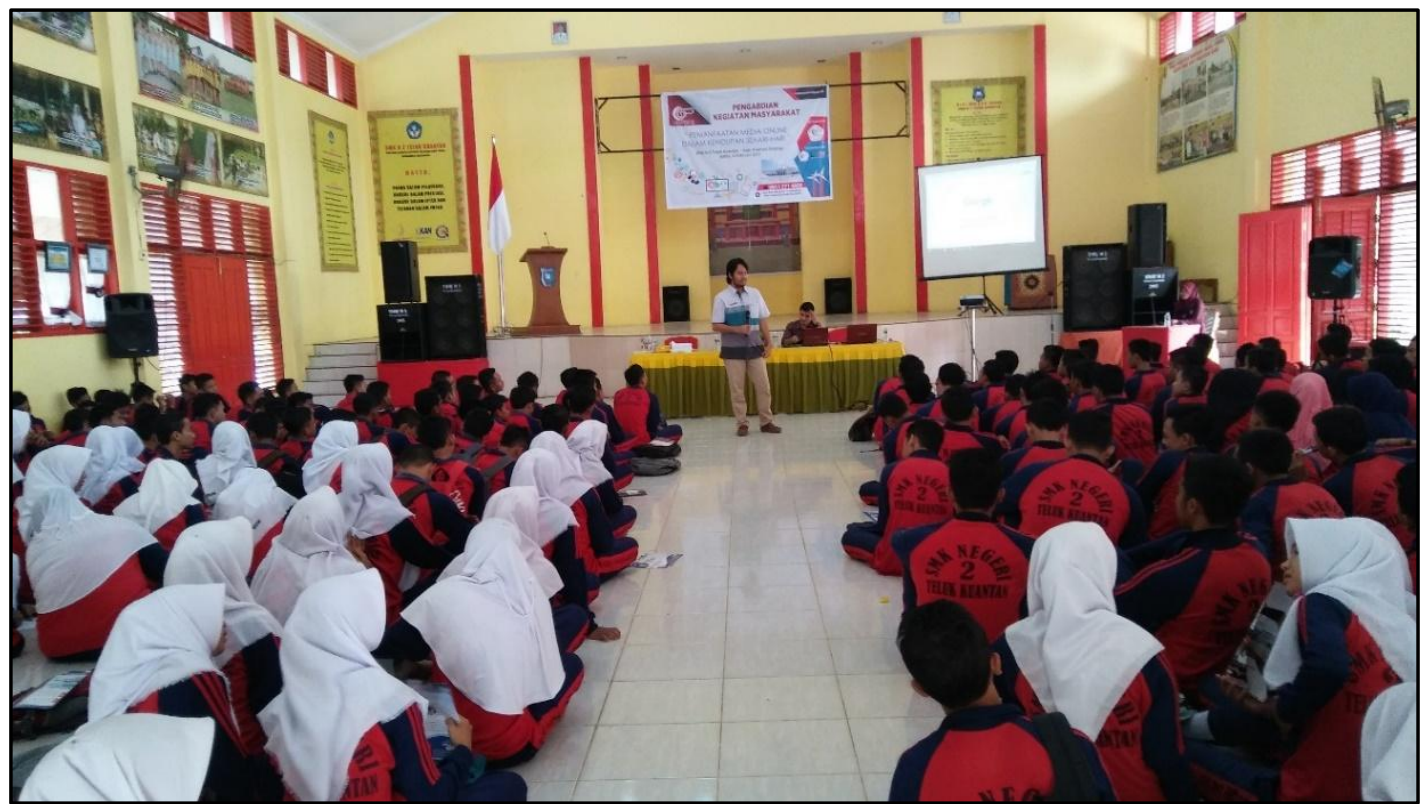

\section{Gambar 3. Pelaksanaan Acara}

Pada sesi demo dijelaskan mengenai konsep power searching dengan simbol matematika yang disisipkan dengan kata kunci pada mesin pencari untuk menyaring informasi seperti berikut ini:

1. Simbol pertama yang sangat berguna untuk dipakai adalah tanda plus (+). Tanda plus dipergunakan jika seorang netter ingin mencari berbagai dokumen dengan kata kunci lebih dari satu. Contoh: +tutorial +merakit +komputer. Yang dilakukan oleh mesin pencari jika menemukan formatsemacam ini adalah mencari berbagai sumber dokumenmaupun artikel yang ada di seluruh internet dimana didalamnya terdapat kata "tutorial", "merakit", dan "komputer".Jika terdapat sebuah dokumen yang mengandung salahsatu atau dua kata yang ada, maka yang bersangkutantidak akan ditampilkan.

2. Simbol lainnya yang sering dipergunakan mendampingi "+" adalah simbol minus (-). Untuk lebih mudah, simbol tersebut dapat dibaca sebagai "kecuali". Contoh: +kampus +jurusan +teknik +informatika +di +Riau -Pekanbaru. Dengan format di atas maka search engine yang bersangkutan akan mencari di internet seluruh dokumen yang mengandung teks "kampus", "jurusan", "teknik", "informatika", "di", "Riau" namun tidak terdapat kata "Pekanbaru" di dalamnya.

3. Di dalam satu pencarian, sebuah kata OR dapat dipergunakan beberapa kali, seperti: laptop OR komputer OR tablet. Hasil yang akan menampilkan daftar 
dokumen yang memiliki satu atau lebih dari kata-kata "laptop", "komputer", "tablet" (termasuk kombinasi antara 2-3 kata tersebut).

4. Simbol berikutnya yang memiliki fungsi kurang lebih sama dengan tanda plus pada simbol matematika adalah AND, yang dapat diterjemahkan sebagai kata "dan" di dalam bahasa Indonesia. Contoh dari penggunaan simbol ini adalah sebagai berikut:tutorial AND linux AND ubuntu. Hasil yang dimunculkan adalah mesin pencari akan mencari seluruh dokumen di internet yang di dalamnya terkandung tiga buah kata, yaitu "tutorial", "linux", dan "ubuntu".

5. Jika di dalam model simbol matematika terdapat tanda minus (untuk merepresentasikan kecuali), maka dalam model simbol boolean terdapat sebuah kata NOT untuk merepresentasikan hal yang serupa. Contoh: harga AND laptop AND 2017 NOT Dell.

6. Diperkenalkan kepada siswa tentang bagaimana menggunakan pencarian dengan menggunakan host, URL dan jenis file yang spesifik pada ujung kata kunci seperti:

a. Bila seorang Guru ingin mencari berbagai referensi yang berkaitan dengan perkembangan harga handphone di situs terkemuka semacam www.lazada.com, maka yang bersangkutan dapat melakukannya dengan memakai kata kunci sebagai berikut: tharga thandphone host:lazada.comatau +harga +handphone inurl:lazada.com

b. Sering sekali para pengguna internet ingin mencari file-file dengan format tertentu di internet untuk di-download, maka yang bersangkutan dapat dengan mudah melakukannya di internet dengan menggunakan perintah "filetype". Contohnya adalah pada search engine Google. Seorang siswa yang ingin mencari artikel tentang teknik merakit kabel LAN dapat menggunakan searching key sebagai berikut:+teknik +merakit +kabel +LAN filetype:pdf.

Kegiatan berlangsung dari pagi hingga siang hari, kegiatan disambut dengan penuh antusias oleh siswa di SMK N II Taluk Kuantan. Setelah sesi demo dan pemaparan materi selesai, kegiatan selanjutnya adalah sesi tanya jawab seperti yang terlihat pada gambar 4: 


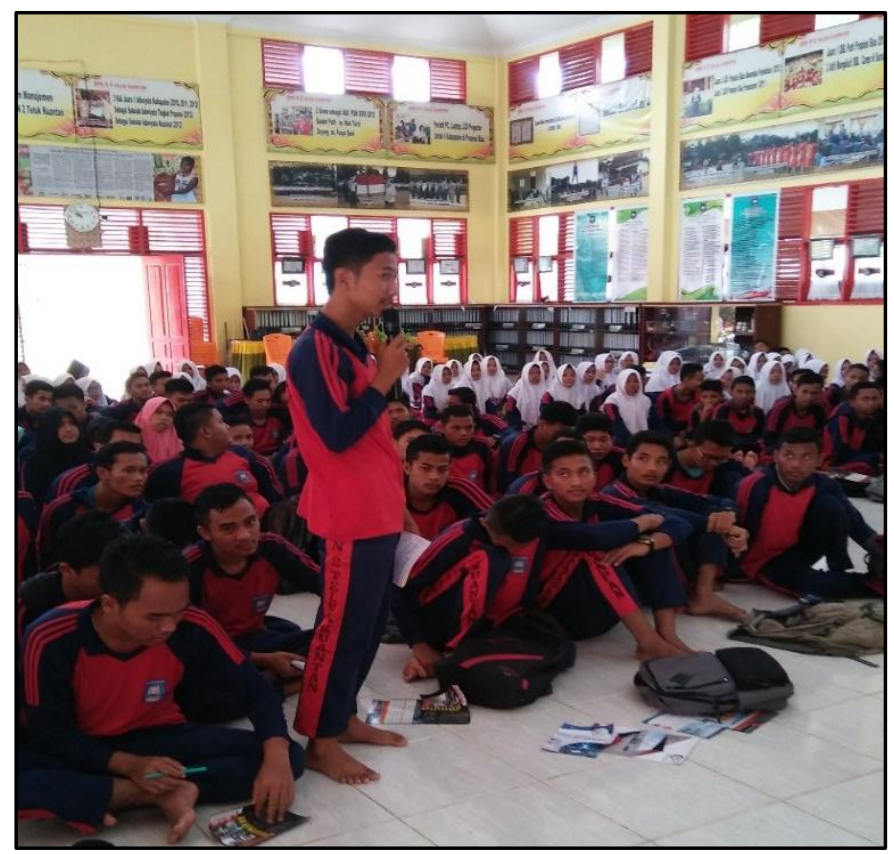

\section{Gambar 4. Sesi Tanya Jawab}

Satu bulan setelah diadakan kegiatan ini, tim melakukan evaluasi terhadap implementasi materi yang telah disampaikan. Hasilnya para siswa di SMK N II Taluk Kuantan dapat mengimplementasikan materi-materi yang telah disampaikan sebelumnya, sehingga para siswa dapat mencari referensi di internet dengan hasil pencarian yang lebih baik dengan power searching.

\section{KESIMPULAN} berikut:

Pada kegiatan pengabdian masyarakat ini, dapat diambil kesimpulan sebagai

1. Siswa SMK N II Taluk Kuantan memiliki semangat belajar dan rasa ingin tahu yang tinggi dalam hal mencari referensi di internet, walaupun memiliki keterbatasan akses internet dan bahkan tidak memiliki peralatan yang dapat terkoneksi internet seperti laptop atau smartphone.

2. Kegiatan pengabdian ini bertujuan untuk memberi pengetahuan kepada siswa di SMK N II Taluk Kuantan tentang bagaimana cara mengoptimalkan hasil pencarian di mesin pencari dengan power searching menggunakan simbol matematika.

3. Pada power searching, disisipkan simbol matematika seperti,,$+- /$, *, And, Or. Selain itu dapat juga ditambahkan akhiran kata "host", "inurl" dan "filetype" untuk hasil pencarian yang lebih spesifik.

4. Siswa di SMK N II Taluk Kuantan dapat mengimplementasikan tentang power searching, dan siswa dapat mencari referensi di internet dengan hasil pencarian yang lebih baik.

\section{UCAPAN TERIMAKASIH} kepada:

Ucapan terimakasih atas terlaksananya kegiatan pengabdian ini disampaikan

1. Universitas Abdurrab melalui LPPM yang telah memberikan bantuan hibah 
pengabdian.

2. Dekan Fakultas Teknik yang telah memberikan persetujuan dan motivasi dalam terlaksananya kegiatan ini.

3. Bapak Yusfig, M.Kom selalu ketua jurusan Teknik Komputer dan jaringan SMKN II Taluk Kuantan, yang telah membantu pelaksanaan kegiatan dari awal survey, pelaksanaan, hingga selesai acara.

4. Sri Novika Sari dan Wili Oktanti, Mahasiswi program studi Teknik Informatika Universitas Abdurrab yang telah membantu terlaksananya kegiatan ini dari awal hingga akhir acara.

\section{DAFTARPUSTAKA}

[1] Hamka, Arif. 2015. Efek Video Tutorial Online Dalam Kegiatan Ekstrakurikuler Animasi Di SMKN 7 Samarinda. Jurnal llmu Komunikasi, ISSN 2502-5961, Hal. $628-638$.

[2] Indrajit, Ricardus Eko. 2002. Teknik Searching Efektif di Internet. Ebook. [Diakses 3 Januari 2017]

[3] Maretina, Sonia. 2016. Digital Information Fluency Pada Mahasiswa Universitas Airlangga. Skripsi. Universitas Airlangga, Surabaya. Hal. 12-14.

[4] Suartama, I Kadek. 2010. Pengembangan Mutimedia Untuk Meningkatkan Kualitas Pembelajaran Pada Mata Kuliah Media Pembelajaran. Jurnal Pendidikan dan Pengajaran, Jilid 43, Nomor 3, Oktober 2010, P-issn 2301-7821 | e-issn 2549-2608. Hal.253-262

[5] Tyas, Dyah Listianing, dkk. 2016. Pengukuran Kesenjangan Digital Masyarakat Di Kota Pekalongan. Seminar Nasional Teknologi Informasi dan Komunikasi 2016 (SENTIKA 2016) ISSN: 2089-9815. Hal. 590-598.

[6] Wahyono, S. Bayu. 2011. Optimalisasi Program Desa Informasi Melalui Penguatan Kelembagaan. Jurnal Penelitian IPTEK-KOM Volume 13, No. 2, Desember 2011. e-ISSN 2527 - 4902 | p-ISSN 4410 - 3346. Balai Pengkajian dan Pengembangan Komunikasi dan Informatika (BPPKI) Yogyakarta. Hal. $125-142$

[7] Wahono, Romi Satria. 2008. Teknik Pencarian Efektif Dengan Google. Artikel Internet. [Diakses 3 Januari 2017]. 